\title{
Technological Readiness Index (TRI) and the intention to use smartphone apps for tourism: A focus on inDubai mobile tourism app
}

\author{
Yosra Jarrar $^{a^{*}}$, Ayodeji Olalekan Awobamise ${ }^{\mathrm{b}}$ and Pedro Sigaud Sellos ${ }^{\mathrm{a}}$
}

\author{
${ }^{b}$ Kampala International University, Uganda

\section{H R O N I C L E} \\ Article history: \\ Received: April 20, 2020 \\ Received in revised format: May \\ 27, 2020 \\ Accepted: May 27, 2020 \\ Available online: June 1, 2020 \\ Keywords: \\ Technological Readiness Index \\ Optimism, Innovation \\ Insecurity \\ Discomfort \\ InDubai app
}

${ }^{a}$ American University in Dubai, United Arab Emirates

\section{A B S T R A C T}

The study sought to find out the effect of Technological Readiness Index (TRI) on the adoption of the inDubai application by potential tourists to Dubai. The finding showed a distinct relationship between TRI dimensions and the intention to make use of the inDubai mobile application. The findings of the study further proved that the TRI model as developed by Parasuraman can indeed prove the intention of individuals to adopt a new technology. The study showed that if the first two dimensions (Optimism and Innovation) are present, then a traveler will most likely see the perceived benefits of using the product or technology which in turn will lead to a positive intention to adopt such a technology. The findings also showed that if the last two dimensions (Insecurity and Discomfort) are present then such individuals exhibiting these behaviors are less likely to want to adopt this new technology. This implies that applications like the inDubai application and other similar applications need to address issues that lead to insecurity and discomfort among users if they are to attract a lot of adopters.

\section{Introduction}

The word smart is commonly associated with any development that leverages on the internet and other technologies that allow for interactivity and exchange of information amongst other things. Hojer and Wangel (2015) argue that what makes something smart goes beyond the individual advances in technology, but is more related to the interconnection, synchronization and concerted use of different technologies. The term 'smart' has even been coopted in economics, with smart economy gradually becoming a thing and referring to technologies that support new forms of collaboration and value creation that lead to innovation, competitiveness and entrepreneurship (Koo, Gretzel, Sigala, \& Xiang, 2015). Smart tourism is increasingly becoming popular and even sought after. In China and South Korea, governments are making serious investments in initiatives and ideas that focus on building technological infrastructures and solutions that support smart tourism (Hwang et al. 2015). The same trend can also be noticed in Europe, where many smart city projects-which by extension lead to and drive smart tourism- are increasingly becoming popular. Europe according to Lamsfus et al. (2015) and Boes et al. (2015) has mostly been focused on providing end user applications that enrich the tourism experience. These solutions usually come in the forms of mobile applications that make tourism more enjoyable for the end user. According to Li et al. (2017), smart tourism is "the ubiquitous tour information service received by tourists during a touring process". Smart devices have helped make tourism easier and even more enjoyable for the average tourist. Smart devices help tourists acquire necessary information, save cost, locate memorable locations and fun things to do, and make the entire tour more enjoyable (Wang et al., 2016).

* Corresponding author.

E-mail address: yjarrar@aud.edu (Y. Jarrar)

(C) 2020 by the authors; licensee Growing Science, Canada. doi: $10.5267 /$ j.ijdns.2020.6.003 
From the foregoing, it appears that 'smartness' is not just a thing, but is here to stay. In practice, the term 'smart' has become highly politicized, and is mostly linked to environment friendly or green initiatives and is no longer necessarily about connectedness and interconnections, but more about how green an initiative is. It is now wielded as a tool to sell political agenda viewpoints and technological solutions and innovations than anything else (Koo, Gretzel, Sigala, \& Xiang, 2015). A lot of the 'smartness' in smart tourism in most cases does not go beyond providing free Wi-Fi's and internet connections in strategic locations to 'enhance' the touristic experience. There is also a concern that the development of applications does not in itself constitute smart tourism. Koo et al, go on to explain that while these are all important steps in actualizing a true smart tourism industry, they do not capture the entirety of what smart tourism means or should mean.

Dubai is a major city in the Middle East and North Africa (MENA) and is one of the most popular tourist destinations in the region and the entire world. Dubai's rapid growth and development in the last 20 years makes it one of the economic and developmental wonders of the world. Dubai in particular has obviously focused most of their developmental initiatives on tourism and their policies make it quite clear that they want tourism to be a central theme in the developmental story. In 2016 alone, Dubai received over 14 million tourists from all over the world, ranking it $4^{\text {th }}$ after Bangkok, London and Paris. The government of Dubai is not slowing down and has no plans to slow down anytime soon, according to a report by Classy Dubai, one of the top and most credible lifestyle blogs based in Dubai, the government has plans to increase tourists' numbers to 20 million every year from the year 2020. Dubai has leveraged on the following strategies to ensure that they keep attracting tourist of all classes and economic strata into their country year in and year out:

1. Affordable offers: Dubai is perhaps one of the most affordable tourist destinations in the world, despite having some of the world most luxurious and expensive hotels; Dubai in a way has a way of attracting all classes. Dubai is a popular destination for Nigerians and citizens of other developing nations, because it provides a beautiful experience at a very affordable price.

2. Beautiful architecture: Dubai has some of the most beautiful architectural master pieces and even engineering wonders in the world today and this has become one of the major selling points to attract tourists into the country. People will travel far and wide just to see these architectural wonders.

3. Hospitality industry: Dubai is home to some of the most luxurious hotels and also home to affordable but stunning hotels, making it the perfect getaway for people of all classes.

The above are just a few of the attractions for potential tourists looking for where to spend the next holiday. Perhaps one of the greatest marketing tools for the tourism industry in recent years is the smart city initiative developed in Dubai. According to Smart Dubai, this initiative has provided a great opportunity for the emergence and use of smart technologies to build the city of the future. Nonetheless, it is still an uphill task to achieve the 20 million yearly visitors from 2020 target. To achieve this, new and novel initiatives must be encouraged. Different applications aimed at attracting and keeping tourists fascinated and interested have been birthed to boost the tourism industry and to also leverage on the popularity of Dubai as a tourist destination. More studies on tourism as it relates to technology have mostly focused on how technological devices play a positive role in enhancing the tourism experience (Buhali \& Amaranggana, 2015; Pradhan, Oh \& Lee, 2018). Not many studies have looked at some of the problems' tourists may face using these smart devices. It is not beyond reason to assume that some tourists might be worried about privacy and the safety of their financial information and even safety from stalkers. The challenges faced by these travelers/tourists visiting Dubai and other touristic locations have not been properly studied in detail and are relatively unknown. Buhali and Amaranggana (2015) studied the negative experiences of IT-based tourism and the findings showed that tech-savvy tourists identified various factors that negatively impacted their tourism experience, some of which include, security concerns, poor internet connections, and navigation. While it is clear that some work has been done on the negative impact of ICT-related tourism, not many studies have looked at how these negative impacts or challenges have impacted the adoption or use of smart tourism applications and technologies by tourists in Dubai.

The inDubai app is a mobile application developed by Majdala Merhebi, Abdulrahman Bin Thalith, Zaina Mohammed and Diala Ali Dimachk to provide a digital local guide platform to showcase great touristic locations in and around Dubai, it acts as a local guide (with the application, one will basically not need a local guide) and provides tidbits about Dubai and other locations around the city. This study examines how drivers and inhibitors of the use of new technology (as stipulated in the TRI model) influence tourists' decisions or intentions to use mobile phone applications for tourism. The study focuses on inDubai app and based on the findings of this study explains how the application addresses some of the concerns and challenges identified as highlighted by the Technology Readiness model. The technology readiness model explains an individual's attitude towards a new technology (Walczuch, Lemmink, Streukens, 2007; Yoo et al., 2017). Therefore, this study will leverage on the model developed by Parasuraman (2000) to explain how tourists to Dubai perceive smart technology in tourism.

\section{Literature Review}

\subsection{Understanding Smart Tourism}

Like most things in life, becoming 'smart' is a national progression, smart phones evolved from the analog telephones, to the digital and to their current form. Cities are gradually evolving into smart and green cities. This phenomenon is present in practically every facet of human development and it is therefore not farfetched to assume the same thing is happening in the 
tourism industry. It is generally accepted by academicians studying this phenomenon, that smart tourism is a natural progression from old-style tourism and e-tourism. Buhalis and Amaranganna (as cited in Pradhan et al, 2018) argue that the idea of smart tourism began with the development, growth and popularity of smart cities around the world. The major driving force for the growth of the smart tourism or e-tourism is the ubiquity of the internet and internet-ready devices. Wang et al. (2016) defines smart tourism as an "ICT-integrated tourism platform" that integrates tourism services with the use of ICT, such as the internet of things, artificial intelligence and cloud computing. The growth and the availability of the internet and other technologies have helped make the smart tourism industry grow and evolve (Li, 2017; Del Vecchio, 2018). Virtual Reality is increasingly growing in popularity as a tool used to support traveler decision making, and establishing strategies for branding and at the same time promoting visitor participation. There are various VR projects being developed to help tourists acquire relevant information about their preferred destination and travel experience through their mobile phones, smart glasses, smartphone applications and other cutting-edge technologies and innovations (Garau, 2017; Boletsis, \& Chasanidou, 2018). Market trends and current technological realities have transformed the approach of doing business in the tourism industry. Furthermore, technological advances have provided a way to address the issues present in the old-style tourism industry.

From the definitions and conceptualization of smart tourism, it is clear that the development and use of mobile phone applications (such as inDubai app) to facilitate tourism by providing customized and targeted information about a particular city (such as Dubai) for the benefit of the tourist with the purpose of ensuring a seamless and enjoyable tourist experience, fits into the concept of smart tourism. However, more research is needed to understand smart tourism from the perspective of mobile phone applications as a complimentary tool to enhance the tourism experience. In other words, tourists' behavior and their choice to make use of smart tourism tools (mobile applications and other technologies) to enhance their tourism experience has not been properly studied and therefore presents a gap this research hopes to bridge.

\subsection{Pros and Cons of Smartphone Applications in Tourism}

Smart applications in this study refer to any mobile phone application and technology that can be used to enhance the tourism experience. So what is the value or perceived value of these applications? Perceived value is a concept that by its very definition is subjective. It is subjective in the sense that the value of something is different and unique to different individuals and means different things to different people. This value is influenced by risks and benefits which are dynamic in nature (Snoj, Pisnik Korda, \& Mumel, 2004). According to Zeithaml (1988), perceived value is "the consumer's overall assessment of the utility of a product (or service) based on perceptions of what is received and what is given". Perceived value is what is left after the cost/risk have been deducted from the perceived benefits, therefore, if the cost or risk is higher than the perceived benefit, then such a technology, product or service has no value in the minds of the consumer (Lovelock, \& Lovelock, 1991, as cited in Pradhan et al., 2018). Various studies have focused on perceived value instead of perceived benefits to understand the benefits of using smart technologies (Pradhan et al., 2018; Cronin, Brady \& Hult, 2000; Yu, et al., 2015). However, this study shall study the perceived benefits and perceived risk separately in order to have a more birds-eye view of the issue being addressed. There are various benefits of using smart devices and smart phone applications in tourism. It makes information concerning a tourist destination, city, activity, product, food, lifestyle amongst many others, easily accessible to the average tourist with a smart phone with the right applications installed. According to Chung, Lee and Han (2015), with smart devices and mobile tourism applications such as inDubai app, tourists can be better informed and can make informed decisions.

According to Jennings, Brady and Han (2015), tourists generally go through three phases while touring and these phases are; the anticipatory phase, the experiential phase and the reflective phase. Throughout these phases, tourists make use of their smart phones and mobile apps to seek out information, make plans, make restaurant reservations, go shopping and dining, capture and share special moments and also reflect on those special memories all from the comfort of their smart devices. The increasingly popularity of VR technology now even makes it possible for tourists to get psychologically ready for the experience by virtually experiencing it on their mobile devices using VR technology. On the other hand, smart tourism is not without its risks. Wang and Wand (2010) argue that these perceived risks can impact the perceived value users get when making use of such products. Their study focused on online hotel reservations and their findings showed that perceived risks invariably influence people's intention to make an online hotel reservation. Buhalis and Amaranganna (2015) found out that security issues, ease of use of software, poor internet accessibility affect perceived usefulness, behavioral intention and attitude in online travel bookings. However, these studies found that risks is also a relative concept and that those that are familiar with smart devices and all the advantages they bring along might have a different perception about usefulness and value than those who are not familiar with such devices.

\subsection{Technology Readiness Index (TRI) and Smart Tech Usage}

The technology Readiness Index (TRI) was developed by Parasuraman (2000) who posits that technology plays an important role in service marketing. The TRI measures individual's readiness to adopt and make use of new technologies. The model depicts people's feelings and attitudes towards an identified new technology. It does not seek to identify how well people know how to use a technology, but rather focuses on their acceptance of such a new technological innovation. The TRI makes use of two factor components, namely; drivers and inhibitors of a new technology usage. This model can therefore be used to measure the benefits and risks of using tourist apps (a focus on inDubai) by tourists travelling to Dubai. Parasuraman and Colby (2001) improved on the TRI model by suggesting four dimensions or behaviors that need to be considered when measuring the TRI, namely; optimism- this is a positive view about the technology which leads the efficiency in life. The second 
dimension is innovativeness, which increases the likelihood to become an early adopter of new technology. The third is insecurity, which usually arises due to concerns about privacy, security and general distrust of technology. The fourth dimension is discomfort, which comes about as a result of the need to control which invariably leads to a sense of being overwhelmed. These dimensions as propounded by Parasuraman and Colby (2001) explain the mental readiness of individuals to accept and make use of a new technology. Optimism and innovativeness are drivers, while insecurity and discomfort are inhibitors. Numerous studies have made use of the TRI to measure the readiness of tourists to make use of technologies to enhance their touristic experience. Liljander et al (2006) studied how the four dimensions of TRI might be impacting users' attitude towards and their readiness to accept or adopt online flight check-in. Their findings showed that TRI does not have a significant impact on customer attitudes towards self-service or online check-ins. A similar study by Elliott et al (2008) sought to find out how TRI influences individuals' willingness to use a new technology. The study was a comparative study comparing American and Chinese markets. The findings showed that American consumers are more likely to make use of self-service technologies to complete retail transactions, than their Chinese counterparts. Hemdi et al. (2016) conducted a study similar to that of Lijander et al (2016) and found out that, optimism and innovativeness significantly impact consumers' decision to continue using self-service check-in, while insecurity does not.

Chung, Han and Joun (2015) in their study on Augmented Reality (AR) for tourism and its relationship to perceived usefulness, attitude, usage intention and destination visit intention, found out that tourists' technological readiness is a predictor of perceived usefulness which in turn affects the intention to use AR and the decision regarding the destination. A study by Wang et al. (2017) sought to also study how technology can be used to enhance the tourists' experience; using Technology readiness as the independent variable and satisfaction and future behavior as the dependent variables, they found out that optimism and innovativeness (drivers) moderate the effect between the perceived quality of the technology, tourist satisfaction and their future behavior. From the foregoing, it is clear that while a lot of studies have been carried to measure the TRI among users and potential adopters of a new technology, very little has been done on the tourism industry and in particular on how mobile applications developed for improving and simplifying the tourists' experience are being influenced by the behavior of the consumers which Parasuraman and Colby (2001) referred to as the four dimensions or behaviors that need to be considered when measuring TRI- optimism, innovativeness, insecurity and discomfort. It is therefore on this basis that this study was conceived.

\subsection{Conceptual model and hypotheses}

This study shall adapt the model (figure 1) developed by Pradhan, Oh and Lee (2018) in their work on "Understanding travelers' behavior for sustainable smart tourism: A Technology Readiness Perspective". The model was developed to measure how the four dimensions in the TRI affect perceived benefits and risks of smart-device usage intention while travelling. While the study does not specifically study mobile applications or tourists' behavior in particular, the fundamental principles of the theory remain relevant to this study. Similar to Pradhan, Oh and Lee, this study shall also consider some moderating factors such as age, gender, income levels, level of education and frequency of travel. The rationale behind considering these moderating factors is that these factors might significantly impact the expected or hypothesized outcome on finding out the relationship between TRI dimensions and perceived usefulness, benefits and risk of tourism enhancement mobile applications.

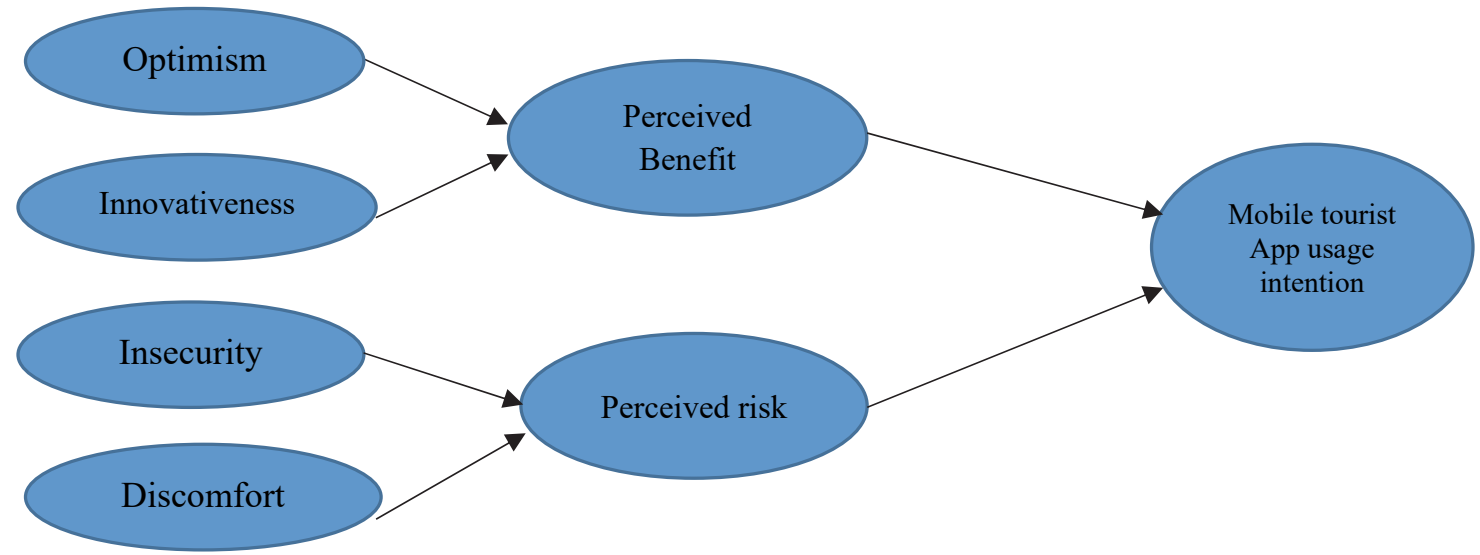

Fig. 1. Conceptual model based on the TRI model to measure intention to use mobile tourist applications (inDubai App)

Source: Adapted from Pradhan, Oh and Lee (2018)

Optimism in the model above can be described as the belief that one will have a good experience in life or the outcome of an activity will generally be positive. The optimist will accept the challenge of trying out a new mobile application while travelling and will try as much as possible to make positive use of the application throughout the trip. The optimist according to Pradhan, Oh and Lee (2018) also "considers smart devices to be more convenient". Since the application being studied here is a mobile application, the researchers assume the same holds true for optimistic travelers making use of mobile phone applications to complement their travels. It can therefore be deduced that optimism leads to a positive, constructive attitude 
and feeling towards mobile applications specifically designed to make tourism more enjoyable and cheaper. Nugroho and Fajar (2017), in their study on TRI effects on the acceptance of mandatory web-based attendance system found out that optimism does in fact influence the intention to use web-based attendance system. In line with this, this study therefore seeks to confirm or refute the following hypothesis:

Hypothesis 1 (H1): Optimism is positively associated with the perceived benefits of mobile applications for tourism.

According to Rogers (2002), Innovativeness can be described as "the degree to which an individual or other unit of adoption is relatively earlier in adopting new ideas than other members of a social system. Midgley and Dowling (1978), also describe it as the "willingness of an individual to try out new information technology". Based on this definition, we surmise that we can measure the degree to which an individual accepts and is willing to adopt a new technology. Therefore, if the acceptance and adaptability of mobile tourism apps are high, then we can surmise that innovativeness is positively associated withthe perceived benefits. Nugroho and Fajar (2017), in their study on TRI effects on the acceptance of mandatory web-based attendance system also studied the effect of innovation on the intention to use web-based attendance system and found out that indeed there is a positive relationship between innovation and intention to use web-based attendance system. Based on this, we developed the second hypothesis:

Hypothesis 2 (H2): There is a positive association between innovativeness and the perceived benefits of mobile applications for tourism.

According to Kwon and Chidambaram (2000), some people do not make use of a new technology because of their fear or phobia of new technology. This fear often leads individuals to avoid making use of these technologies when other alternatives are present. One of the main concerns for users of smart technologies is the issue of personal security and privacy. Intrusiveness of some technologies can sometimes make people lose the will to try them out. The feeling of insecurity can invariably lead to discomfort. Discomfort in this model according to Parasuraman (2000) is a "perceived lack of control over technology and a feeling of being overwhelmed by it". Not everyone is willing to make use of mobile phone applications, because while they might be easy to download and install, some of them are still too complicated to maneuver. Such personal discomfort can be a reason for tourist not making use of such applications especially when they feel the risk far outweighs the perceived benefits. Therefore, we deduce the following hypotheses;

Hypothesis 3 (H3): There is a positive relationship between insecurity and the perceived risk of mobile applications for tourism.

Hypothesis 4 (H4): There is a positive relationship between discomfort and the perceived risk of mobile applications for tourism.

Perceived benefits can be referred to as the positive consequences or results that are caused by a specific action. In the context of this study, perceived benefits shall mean positive results that are directly linked to making use of mobile application for tourism. It has been established through empirical studies that perceived benefits are positively associated with the intention to make use of smart devices (Hubert, et al., 2019; To, Lee \& Lam, 2018)

As argued earlier, the intention to use smart devices and the intention to make use of mobile apps are intertwined, considering that the applications usually work and power most of the functions on smart devices and phones. The inDubai mobile app is compatible with any smart phone in the market today and makes the process of searching for information about a particular touristic attraction in Dubai, popular markets, fine restaurants, safaris easier. The application also helps tourist navigate Dubai, while pinpointing and directing them to truly breathtaking locations around the region. Therefore, we can infer that the perceived benefits of mobile phone applications for tourism are positively associated with the intention to make use of them while travelling. However, while the benefit might be related with the intention to make use, the perceived risk associated with making use of mobile phone applications might negatively impact travelers' intention to make use of the application. Perceived risk can be described as an individual's evaluation based on different factors of the risk associated with carrying out an action. In the context of this study, risk manifests in form of security, safety and other privacy issues (Marafon, 2018; Belkhamza \& Wafa, 2009; Nguyen \& Nguyen 2017). This leads us to the next set of hypotheses:

Hypothesis 5 (H5): The perceived benefit of making use of Smart phone applications for tourism is positively associated with the intention to make use of the app when travelling.

Hypothesis 6 (H6): There is a negative association between the perceived risks of using smart phone applications for tourism and intention to use the application while travelling.

\section{Methodology}

A survey was used to collect the required data from people living in Lagos, Nigeria. With Lagos being the most populous and getaway point for most Nigerians seeking to travel to Dubai, it made sense to make use of Lagos, Nigeria as the study area. The questionnaire had 37 questions and 8 sections including the demographic section, the sections are, optimism, innovativeness, (adopted from Chung, Han and Joun, 2015), insecurity, discomfort (adapted from Walczuch, Lemmink and Streukens), perceived benefits, perceived risk (adapted from Kim, Ferrin and Rao,) and smart device usage intention (adapted from Chung, 
Han and Joun). The questionnaire made use of the likert scale from 1-5 with 1 being strongly disagree and 5 being strongly agree. A total of 300 responses including 201 local traveler and 99 international ones were collected. An attempt was made to ensure a balance between the demographic data (age, gender, education, experience using mobile applications and frequency of travel) to ensure that the findings are as objective and conclusive as possible without the possibility of selection bias being present. The table below shows the breakdown of the sample characteristics.

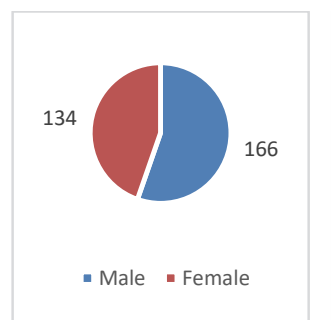

Gender

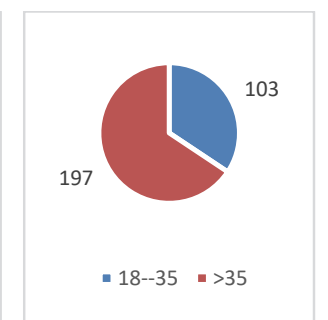

Age

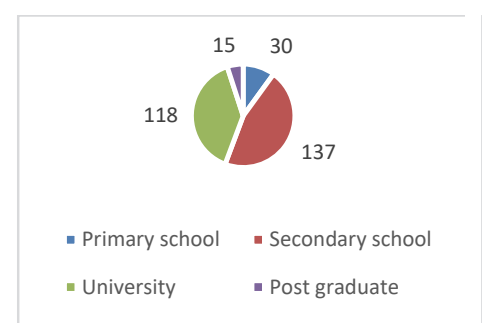

Educational background

Fig. 2. Personal characteristics of the participants

\section{Results and Discussion}

The researchers used Pearson's correlation test to determine the relationship between the various variables in this study. The findings for hypothesis 1-6 are detailed in the table below.

Table 1

Hypothesis $1-6$ test results

\begin{tabular}{|c|c|c|c|c|}
\hline Hypotheses & R value & Sig. (2-tailed) & Results & Hypothesis test \\
\hline $\begin{array}{l}\text { H1: Optimism is positively associated with the perceived benefits of mobile ap- } \\
\text { plications for tourism. }\end{array}$ & .587 & .000 & Positive relationship & Accepted \\
\hline $\begin{array}{l}\text { H2: there is a positive association between innovativeness and perceived benefits } \\
\text { of mobile applications for tourism }\end{array}$ & .331 & .000 & Positive relationship & Accepted \\
\hline $\begin{array}{l}\text { H3: There is a positive relationship between insecurity and perceived risk of mo- } \\
\text { bile applications for tourism. }\end{array}$ & .709 & .000 & Positive relationship & Accepted \\
\hline $\begin{array}{l}\text { H4: there is a positive relationship between discomfort and perceived risk of mo- } \\
\text { bile applications for tourism. }\end{array}$ & .234 & .000 & Positive relationship & Accepted \\
\hline $\begin{array}{l}\text { H5: The perceived benefit of making use of Smart phone applications for tourism } \\
\text { is positively associated with the intention to make use of the app when travelling. }\end{array}$ & .119 & .008 & Positive relationship & Accepted \\
\hline $\begin{array}{l}\text { H6: there is a negative association between the perceived risks of using smart } \\
\text { phone applications for tourism and intention to use }\end{array}$ & -0.175 & .000 & $\begin{array}{l}\text { Negative relation- } \\
\text { ship }\end{array}$ & Accepted \\
\hline
\end{tabular}

The results of the Pearson's correlation test for Hypothesis 1 indicate that there is a positive association between optimism and the perceived benefits of using mobile apps for tourism in Dubai, $\mathrm{r}(498)=.175, p=.015$. This implies that the more optimistic an individual is the higher or more positive their perception about the benefits of using mobile phone application for tourism such as inDubai mobile application. Innovativeness has been described in earlier sections of this paper as the degree to which an individual is likely and willing to adopt a new technology at an early stage of release or innovation. The findings for hypothesis 2 as indicated in table 2 above show a strong relationship between innovativeness and the perceived benefits, $\mathrm{r}(498)=.188, p<.0001$. Based on the finding, innovativeness as conceptualized in this study is correlated with the perceived benefits of using a mobile phone application for tourism. That means, the higher the level of innovativeness the higher the level of perceived benefits of using new technology. The researchers therefore assume that people who are innovative (in terms of TRI dimensions) are more likely to be daring and see the positive aspects of a new technology which will lead to the perceived benefits of the technology. The Pearson's correlation test for H3 showed a positive significant relationship between insecurity and the perceived risk, $\mathrm{r}(498)=.545, p<.0001$ which proves the hypothesis right. The implication is that, the more insecure a user feels when using a product, then the higher the perception of risk he/she will attach to making use of the product. In the context of this study, respondents were asked about their insecurities when using the inDubai mobile application for tourism and it was clear that those who felt their safety is compromised when using phone apps, and spending money online, were more likely to have a higher level of perceived risk. From the findings of this study, the researchers deduced that insecurity can also lead to increased levels of discomfort among users of mobile applications. When people feel they are being exploited, being spied upon or their online details can fall into the wrong hands, they are likely to feel some level of discomfort. Discomfort can also manifest in the form of inconvenience of downloading, installing and using the application. According to the results of testing $\mathrm{H} 4$, discomfort has a positive significant relationship with the perceived risk $\mathrm{r}(498)=.632, p<.0001$. The implication is that, the more uncomfortable it is for users to make use and navigate an application, the more likely they are to have higher levels of perceived risks. This is surprising, as it might have been expected that the problem with navigation might have to do with sophistication which sometimes is associated with quality, so the expectation was that the participants will be more comfortable and feel safer using an application that is more sophisticated than the average one. This leads us to recommend that further studies be conducted to find out the predictors of discomfort and perceived risks of using mobile applications and what the most acceptable level of sophistication and complexity is ideal for a mobile application. 
H5 test results show that there is a positive significant relationship between the perceived benefit of making use of smart phone applications for tourism and the intention to make use of the app when travelling $\mathrm{r}(498)=.792, p<.0001$. Therefore, H5 is accepted. It can be deduced that the more perceived benefits users get from a product or in this case, mobile application for tourism, the more likely they are to make use of the application or product. The inDubai application though still in its infancy, already promises to provide useful and highly beneficial features that make the tourism experience for the average tourist more enjoyable and cost-effective. It is perhaps these perceived benefits that has made it quite popular among test subjects so far. Finally, results for H6 test show that there is a negative association between the perceived risks of using smart phone applications for tourism and intention to use the application while travelling $\mathrm{r}(498)=-0.189, p<.0001$. The findings show that the more the perceived risk to travelers, the less likely they will make use of the product. The implication is that apps like inDubai that seek to provide a more fluid, cost effective and enjoyable tourist experience will need to convince potential users that the application is safe to use without any associated risk, otherwise users might be hesitant to make use of the application. The findings of the study further prove that the TRI model as developed by Parasuraman (2000) can indeed prove the intention of individuals to adopt a new technology. This study shows that if the first two dimensions (Optimism and Innovation) are present, then a traveler will most likely see the perceived benefits of using the product or technology which in turn will lead to a positive intention to adopt such a technology. The findings also show that if the last 2 dimensions (Insecurity and Discomfort) are present then such individuals exhibiting these behaviors are less likely to want to adopt this new technology (in this case smart phone applications for tourism - inDubai). The implication of this finding and its real-life application is that applications like inDubai application and other similar applications need to address issues that lead to insecurity and discomfort among users if they are to attract a lot of adopters. Based on the characteristics and features of the inDubai mobile application, it is apparent that the application focuses on the drivers of adoption (as proposed by the TRI model) since it does not seek personal information or details and it does not ask for payments online. The inDubai mobile application also promotes ease of navigation which reduces users' discomfort and increases their likelihood of adopting such mobile application.

\section{Conclusions and Recommendations}

Studies on the adoption of new technologies are not new, however, studies relating to the adoption of smart technologies are relatively new considering the fact that smart technologies are also new. This study focuses on the inDubai mobile application, a technology that seeks to digitize the tourism experience for the consumers. This is a relatively new concept that goes beyond using smart phones to access relevant tourism locations, but also serves as an AI powered tour guide, that saves the consumer money without removing from the tourism experience. As far as the authors are concerned, this is a one of a kind mobile application that has the potential of changing the entire tourism industry. The study sought to find out the effect of TRI on the adoption of the inDubai application by potential tourists to Dubai. The findings show a distinct relationship between TRI dimensions and the intention to make use of the inDubai application. The study however stopped short of analyzing how factors like, income levels, frequency of travels, experience making use of mobile applications, payment variability in the application amongst other things, can moderate the effect of the TRI dimensions on users' intention to make use of mobile phone applications for tourism. It is therefore recommended that further research is done to find out the mediating influence of the factors listed above. Secondly, the TRI model focuses on the intention to use a technology and not on the competencies of the users using new technology. It is therefore the submission of this study, that there is a need for further studies that examine the relationship between the TRI model and how it interrelates with consumer behavior and tech-users' competencies when they make a decision to adopt or reject new products, services or technologies.

\section{References}

Belkhamza, Z., \& Wafa, S.A. (2009). The Effect of Perceived Risk on the Intention to Use E-commerce: The Case of Algeria. Journal of Internet Banking and Commerce, 14(1).

Boletsis, C., \& Chasanidou, D. (2018). Smart Tourism in Cities: Exploring Urban Destinations with Audio Augmented Reality. In Proceedings of the 11th PErvasive Technologies Related to Assistive Environments Conference, Corfu, Greece, 2629 June 2018; ACM: New York, NY, USA, 2018; pp. 515-521.

Buhalis, D., \& Amaranggana, A. (2015). Smart tourism destinations enhancing tourism experience through personalisation of services. In Information and Communication Technologies in Tourism. Berlin, Germany: Springer. 377-389.

Chung, N., Han, H., \& Joun, Y. (2015). Tourists' intention to visit a destination: The role of augmented reality (AR) application for a heritage site. Computer in Human Behavior, 50, 588-599.

Chung, N., Lee, S., \& Han, H. (2015). Understanding communication types on travel information sharing in social media: A transactive memory systems perspective. Telematics and Informatics, 32(4), 564-575.

Cronin, J.J., Brady, M.K., \& Hult, G.T.M. (2000). Assessing the effects of quality, value, and customer satisfaction on consumer behavioral intentions in service environments. Journal of Retailing, 76, 193-218.

Del Vecchio, P., Mele, G., Ndou, V., \& Secundo, G. (2018). Creating value from social big data: Implications for smart tourism destinations. Information Processing Management, 54, 847-860.

Elliott, K.M., Meng, J., \& Hall, M.C. (2008). Technology readiness and the likelihood to use self-service technology: Chinese vs. American consumers. Marketing Management Journal, 18, 20-31.

Garau, C. (2017). Emerging technologies and cultural tourism: Opportunities for a cultural urban tourism research agenda. In Tourism in the City. Berlin, Germany: Springer. pp. 67-80. 
Gretzel, U., Sigala, M., Xiang, Z., \& Koo, C. (2015). Smart tourism: Foundations and developments. Electronic Marketing, $25,179-188$.

Hemdi, M., Rahman, S., Hanafiah, M., \& Adanan, A. (2016). Airport Self-Service Check-in: The Influence of Technology Readiness on Customer Satisfaction. In Proceedings of the 3rd International Hospitality and Tourism. Conference \& 2 nd International Seminar on Tourism, Bandung, Indonesia, 10-12 October 2016; CRC Press/Balkema: Leiden, The Netherlands, 2016.

Hubert, M., Blut, M., Brock, C., Zhang, R., Koch, V. \& Riedl, R. (2019). The influence of acceptance and adoption drivers on smart home usage. European Journal of Marketing, 53 (6), 1073-1098. https://doi.org/10.1108/EJM-12-2016-0794

Jennings, G.; \& Nickerson, N. Quality Tourism Experiences; Routledge: Abingdon, UK, 2006.

Kwon, H.S., \& Chidambaram, L. (2000). A test of the technology acceptance model: The case of cellular telephone adoption. In Proceedings of the 33rd Annual Hawaii International Conference on System Sciences, Maui, HI, USA, 4-7 January 2000; IEEE: Piscataway, NJ, USA.

Li, Y., Hu, C., Huang, C., \& Duan, L. The concept of smart tourism in the context of tourism information services. Tourism Management, 58, 293-300.

Liljander, V., Gillberg, F., Gummerus, J., \& Van Riel, A. (2006). Technology readiness and the evaluation and adoption of self-service technologies. Journal of Retailing Consumption Services, 13, 177-191.

Lovelock, C.H., \& Lovelock, C.H. (1991). Services Marketing. Englewood Cliffs, NJ, USA: Prentice Hall.

Marafon, D.L., Basso, K., Espartel, L.B., Dutra de Barcellos, M., \& Rech, M. (2018). Perceived risk and intention to use internet banking: The effects of self-confidence and risk acceptance. International Journal of Bank Marketing, 36(2), 277-289, https://doi.org/10.1108/IJBM-11-2016-0166

Midgley, D. F., \& Dowling, G. R. (1978). Innovativeness: The concept and its measurement. Journal of Consumer Research, 4(4), 229-242.

Nguyen, T.D. \& Nguyen, T.C.H. (2017). The role of perceived risk on intention to use online banking in Vietnam. Conference paper presented at International Conference on Advances in Computing, Communications and Informatics, India. DOI: 10.1109/ICACCI.2017.8126122

Nugroho, M.A., \& Fajar, M.A. (2017). Effects of technology readiness towards acceptance of mandatory web-based attendance system. Procedia Computer Science 124, 319-328

Parasuraman, A. (2000). Technology Readiness Index (TRI) a multiple-item scale to measure readiness to embrace new technologies. Journal of Service Research, 2(4), 307-320.

Parasuraman, A., \& Colby, C. (2001). Techno-Ready Marketing: How and Why Consumers Adopt Technology. Detroit, MI, USA: Free Press

Petrick, J. F., \& Backman, S. J. (2002). An examination of the construct of perceived value for the prediction of golf travelers' intentions to revisit. Journal of Travel Research, 41(1), 38-45.

Rogers, E. M. (2002). Diffusion of preventive innovations. Addictive behaviors, 27(6), 989-993.

Snoj, B., Pisnik Korda, A., \& Mumel, D. (2004). The relationships among perceived quality, perceived risk and perceived product value. Journal of Production Brand Management, 13, 156-167.

To, W., Lee, P.K., \& Lam, K. (2018). Building professionals' intention to use smart and sustainable building technologiesAn empirical study. PLoS ONE 13(8): e0201625. https://doi.org/10.1371/journal.pone.0201625

Walczuch, R., Lemmink, J., \& Streukens, S. (2007). The effect of service employees' technology readiness on technology acceptance. Information Management, 44, 206-215.

Wang, H., \& Wang, S. (2010). Predicting mobile hotel reservation adoption: Insight from a perceived value standpoint. International Journal of Hospitality Management, 29, 598-608.

Wang, H. Y., \& Wang, S. H. (2010). Predicting mobile hotel reservation adoption: Insight from a perceived value standpoint. International Journal of Hospitality Management, 29(4), 598-608.

Wang, X., Li, X.R., Zhen, F., \& Zhang, J. (2016). How smart is your tourist attraction? Measuring tourist preferences of smart tourism attractions via a FCEM-AHP and IPA approach. Tourism Management, 54, 309-320.

Wang, X., Li, X.R., Zhen, F., \& Zhang, J. (2016). How smart is your tourist attraction? Measuring tourist preferences of smart tourism attractions via a FCEM-AHP and IPA approach. Tourism Management, 54, 309-320.

Wang, Y., So, K. K. F., \& Sparks, B. A. (2017). Technology readiness and customer satisfaction with travel technologies: A cross-country investigation. Journal of Travel Research, 56(5), 563-577.

Yoo, C., Kwon, S., Na, H., \& Chang, B. (2017). Factors Affecting the Adoption of Gamified Smart Tourism Applications: An Integrative Approach. Sustainability, 9, 2162. [CrossRef]

Yu, J., Lee, H., Ha, I., \& Zo, H. (2017). User acceptance of media tablets: An empirical examination of perceived value. Telematics and Informatics, 34(4), 206-223.

Zeithaml, V.A. (1988). Consumer perceptions of price, quality, and value: A means-end model and synthesis of evidence. Journal of Marketing, 52, 2-22.

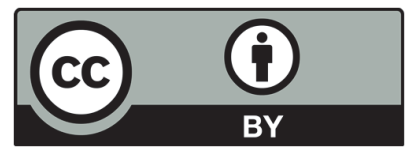

(C) 2020 by the authors; licensee Growing Science, Canada. This is an open access article distributed under the terms and conditions of the Creative Commons Attribution (CC-BY) license (http://creativecommons.org/licenses/by/4.0/). 